\title{
ACEITABILIDADE SENSORIAL DE BISCOITOS ELABORADOS COM FARINHA DE TRIGO SARRACENO
}

\author{
Alice Nogueira Novaes SOUTHGATE ${ }^{1}$ \\ Krischina Singer APLEVICZ²
}

\begin{abstract}
${ }^{1}$ Mestre em Turismo e Hotelaria, Professora do Instituto Federal de Santa Catarina, Campus Florianópolis-Continente, alicen@ifsc.edu.br

${ }^{2}$ Doutora em Ciências dos Alimentos, Professora do Instituto Federal de Santa Catarina, Campus FlorianópolisContinente, aplevicz@gmail.com
\end{abstract}

Recebido em: 16/12/2015 - Aprovado em: 17/07/2016 - Disponibilizado em: 18/12/2016

\begin{abstract}
RESUMO
O trigo sarraceno é um pseudocereal pouco conhecido e subutilizado, apesar do seu grande potencial devido às suas propriedades nutricionais. É um alimento produzido em Santa Catarina, fazendo parte da agricultura familiar. O objetivo desta pesquisa foi desenvolver biscoitos produzidos com farinha de trigo sarraceno e verificar sua aceitabilidade sensorial. Foram desenvolvidas três formulações de biscoito, usando somente farinha de trigo sarraceno. Os biscoitos produzidos foram salgado, doce com canela e cookie. O teste de aceitabilidade foi aplicado a um grupo de julgadores não treinados $(n=50)$ utilizando escala hedônica estruturada de nove pontos. Foi realizada uma análise estatística e as diferenças entre as médias foram calculadas através da análise de variância oneway (ANOVA) com o teste de Tukey. No teste sensorial foi observada diferença significativa entre os tratamentos $(\mathrm{P}>0,05)$. As amostras de biscoito doce com canela e cookie foram aceitas. A elaboração de biscoitos com a farinha de sarraceno tem potencial comercial já que apresentou uma boa aceitabilidade sensorial, especialmente o biscoito tipo cookie.
\end{abstract}

Palavras-chave: trigo sarraceno, biscoitos, gastronomia.

\section{SENSORY ACCEPTABILITY OF BISCUITS PREPARED WITH SENSORY WHEAT FLOUR BUCKWHEAT}

\begin{abstract}
The buckwheat is a pseudocereal a little known and underutilized, despite its great potential due to its nutritional properties. It is a food produced in Santa Catarina, part of the family farm. The objective of this research was to develop biscuits made with buckwheat flour and test for sensory acceptability. Three cookie formulations were developed, using only buckwheat flour. The biscuits were produced salty, sweet with cinnamon and cookie. The sensory evaluation was applied to a group of untrained judges $(n=50)$ using the 9-point hedonic scale. Following a statistical analysis, the differences between means were calculated by using analysis of variance (ANOVA) and Tukey test. In the sensory test was no significant difference between treatments $(\mathrm{P}>0.05)$. The sweet cookie with cinnamon and cookie samples were accepted. The preparation of biscuits with buckwheat flour has commercial potential as it showed a good sensory acceptability, especially the biscuit cookie type.
\end{abstract}

Keywords: buckwheat, biscuits, gastronomy.

\section{INTRODUÇÃO}

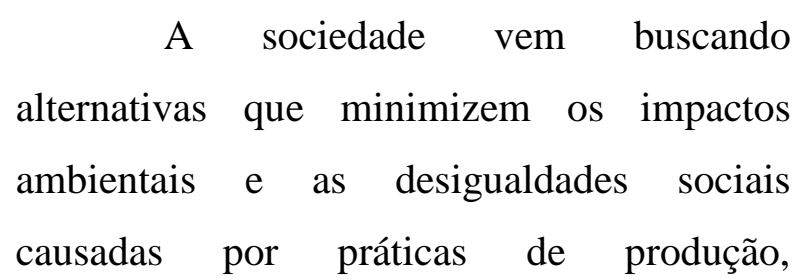

distribuição e consumo cada vez mais insustentáveis (ALTIERI, 2012). Uma maior diversidade nutricional e agrícola dentro do sistema de produção é uma estratégia para melhorar o sistema alimentar (JOHNS; 
EYZAGUIRRE, 2007). A diversidade nutricional e agrícola são, portanto, vistos como essencial e interconectados. Goodman (2003) aponta que a virada da qualidade (quality turn), em linhas gerais, abrangeria a produção de alimentos orgânicos, redes agroalimentares alternativas às hegemônicas, ou seja, alternativas para a garantia de qualidade e estratégias territoriais para valorização de alimentos locais.

As culturas subutilizadas aumentam a diversidade em rotações de culturas e proporcionam novas possibilidades para cultivo do solo. Resultam em maior competitividade do produto, maior valor nutricional e saudabilidade dos alimentos, valorização do produto local e aumento da sua atratividade. As culturas comestíveis subutilizadas englobam os cereais e os pseudocereais, leguminosas, raízes e tubérculos, culturas oleaginosas, corantes, entre outras. Podem ser explorados para a criação de novos nichos de mercado com base na produção e processamento em pequena escala, embora algumas culturas sejam adequadas também para processamento industrial. Algumas dessas plantas são de origem indígena, outras de origem exótica indicando a importância da compreensão do uso de culturas subutilizadas, baseadas na tradição e suas especificidades (BAVEC, 2014).

Os pseudocereais, do ponto de vista da botânica, são plantas dicotiledôneas e, portanto, não são cereais (monocotiledôneas). Por produzirem sementes ricas em amido, assim como os cereais, são denominados "pseudocereais". O amaranto (Amaranthus spp.) e a quinoa (Chenopodium quinoa) são grãos andinos, enquanto o trigo sarraceno (Fagopyrum esculentum) é originário da Ásia Central. Estes grãos possuem uma excelente composição química, com elevado teor proteico. São ricos em aminoácidos essenciais como metionina, lisina, arginina e triptofano; possuem elevado teor de lipídeos insaturados e polinsaturados; são ricos em minerais, como cálcio, magnésio, ferro, potássio e zinco; e também são fontes de compostos bioativos, representando um importante potencial antioxidante (SCHOENLECHNER et al., 2008; ALVAREZ-JUBETE et al., 2010; COMINO et al., 2013).

Utilizado como alimento há centenas de anos, o trigo sarraceno foi introduzido na região sul do Brasil por imigrantes poloneses, russos e alemães, no início do século XX. Nos anos setenta, houve um grande incentivo da cultura do sarraceno no estado do Paraná, que chegou a plantar anualmente, em torno de 1200 toneladas de sementes em área equivalente a aproximadamente 30 mil hectares. A maior parte da produção se destinava à panificação, em mistura com farinha de trigo (Triticum aestivum L.), enquanto que o restante destinava-se a exportação para o Japão, Holanda, Polônia e Estados Unidos. 
Posteriormente, a farinha de sarraceno foi substituída pela raspa de mandioca e fubá de milho. Como consequiência, seu cultivo foi sendo desativado, restringindo-se apenas a pequenas lavouras de subsistência (SILVA et al., 2002).

O trigo sarraceno é considerado uma cultura agrícola de importância secundária em muitos países, e que persistiu através de séculos de civilização. Faz parte da agricultura de quase todos os países em que os cereais são cultivados, principalmente em áreas marginais (FAO, 2000). Por sua grande tolerância à acidez e capacidade de utilização de sais de fósforo e potássio pouco solúveis no solo, consegue um bom desenvolvimento em solos pobres, podendo ser utilizado como adubo verde e para a regeneração de solos esgotados (SILVA et al., 2002; KLEIN et al., 2010). Possuindo um período de floração de aproximadamente 40 dias, é ainda muito procurado pelas abelhas que produzem um mel escuro e de sabor forte (FREITAS, 2013).

Em Itaiópolis, município localizado no Planalto Norte do Estado de Santa Catarina com 20.000 habitantes (VICENTE FILHO, 2013) e essencialmente agrícola, o trigo sarraceno é conhecido principalmente como Tatarca ou "Hretchka" denominação usada mais comumente pelos Ucranianos. Foram os imigrantes eslavos que trouxeram consigo as primeiras sementes da planta por volta de 1890. É dentro das famílias descendentes de eslavos, em especial os ucranianos, que a
Tatarca tem um lugar muito especial, consistindo em uma tradição que vem sendo transmitida de uma geração para outra (FREITAS, 2013).

O grão é geralmente usado como alimento humano e animal. Os grumos descascados são preparados como mingau e a farinha usada na preparação de panquecas, biscoitos, macarrão, cereais etc. A proteína do trigo sarraceno é de excelente qualidade e é alta em lisina, um aminoácido essencial, ao contrário de cereais comuns (RODRIGUES; OLIVEIRA, 2010). Para a indústria de alimentos, os grãos de trigo sarraceno são uma matéria-prima valiosa para ser usado na produção de alimentos funcionais. A farinha pode ser um ingrediente importante nas dietas ou produtos alimentares, tendo em consideração o seu valor nutritivo e potencial para a promoção da saúde humana (CHRISTA; SORAL-ŚMIETANA, 2008).

Capriles et al. (2014) desenvolveram pesquisas com pseudocereais na elaboração de produtos sem glúten, com amaranto e a quinoa e afirmaram que a indústria já começou a incorporar esses grãos em vários produtos, mas a quantidade utilizada ainda é baixa. A situação do trigo sarraceno ainda é mais dramática porque ele já é cultivado no Brasil há mais de 80 anos e é muito difícil encontrar este produto no mercado nacional.

Com o propósito de agregar valor nutricional aos produtos sem glúten, alguns pesquisadores têm investigado o efeito da 
adição de matérias primas que possam melhorar o valor nutricional dos produtos, como as farinhas dos pseudocereais (NASCIMENTO, 2014). Alguns pesquisadores estudaram o potencial do trigo sarraceno na elaboração de biscoitos (BALJEET et al., 2010; TORBICA et al., 2012; HADNAĐEV et al., 2013; CHOPRA et al., 2014). Hoje existe poucas pesquisas no âmbito nacional com esse tema.

Ressalta-se, portanto, a relevância desta pesquisa que buscou a compreensão da importância das culturas subutilizadas, em especial a dos pseudocereais com foco no trigo sarraceno de Santa Catarina. Ainda é possível encontrá-lo proveniente da agricultura familiar em consonância com algumas das tendências da alimentação contemporânea evidenciadas por Barbosa (2009), Cruz e Menasche (2011) como as relacionadas à sustentabilidade e ética. Relataram que os consumidores estão interessados na questão do meio ambiente e também na possibilidade de contribuir para causas sociais ou auxiliar pequenas comunidades agrícolas por meio da compra de produtos alimentícios. Outra tendência citada é o valor da origem e a saudabilidade, que está ligada no valor nutricional dos alimentos e na busca pela saúde e prevenção de doenças, incluindo também a noção de bem estar, envolvendo também aspectos ambientais.

O incentivo ao consumo do trigo sarraceno vai ao encontro dos anseios da sociedade moderna, no entanto, conforme Bavec (2014), no caso das culturas subutilizadas, são necessários conhecimentos e atividades multidisciplinares para a compreensão deste tipo de potencial para estabelecer nichos de mercado e aponta como principal solução um esforço direcionado à educação e pesquisa.

Por todas as qualidades apontadas, tanto no tocante ao cultivo quanto às qualidades nutricionais, esta pesquisa objetivou a valorização do trigo sarraceno a partir do desenvolvimento de biscoitos, verificando a sua aceitabilidade sensorial.

\section{MATERIAIS E MÉTODOS}

\section{Elaboração dos biscoitos}

Os biscoitos foram produzidos no Laboratório de Panificação e Confeitaria do Instituto Federal de Santa Catarina (IFSC). A Tabela 1 apresenta as três formulações de biscoitos elaborados com a farinha de trigo sarraceno. 
Tabela 1 - Formulação em porcentagem dos biscoitos com trigo sarraceno.

\begin{tabular}{lccc}
\hline Ingredientes & Formulação A & Formulação B & Formulação C \\
Farinha de trigo sarraceno & 100 & 100 & 100 \\
Manteiga sem sal & - & - & 74 \\
Azeite de oliva & 30 & 30 & - \\
Sal & 1,5 & - & 1,5 \\
Açúcar mascavo & - & 60 & 100 \\
Bicarbonato de sódio & 1,5 & 1,5 & 1,5 \\
Água & 60 & 60 & - \\
Ovo & - & - & 37 \\
Canela em pó & - & 2 & - \\
Chocolate amargo 70\% em gotas & - & - & 100 \\
Nozes & - & - & 50 \\
\hline
\end{tabular}

Legenda:

Formulação A: Biscoito salgado com trigo sarraceno

Formulação B: Biscoito doce com canela com trigo sarraceno

Formulação C: Biscoito tipo cookie com trigo sarraceno

A formulação A, biscoito salgado com trigo sarraceno sem glúten e sem lactose e a formulação $\mathrm{B}$, biscoito doce com canela com trigo sarraceno sem glúten e sem lactose, foram elaborados da mesma maneira. As sementes de trigo sarraceno foram processadas no liquidificador e depois peneiradas adquirindo-se uma farinha fina. Esta farinha foi pesada e, em seguida, acrescentado o sal ou o açúcar. Após a gordura e a água foram adicionadas, misturando até formar uma massa homogênea com todos os ingredientes incorporados. A massa descansou por 20 minutos para que a farinha absorvesse bem os ingredientes e depois foi aberta com um rolo de massas de prolipropileno na espessura de $0,5 \mathrm{~mm}$, cortados no diâmetro de $5 \mathrm{~cm}$.

$\mathrm{Na}$ formulação $\mathrm{C}$, biscoito doce tipo cookie com trigo sarraceno, foi utilizada a farinha de sarraceno processada da mesma maneira que nas formulações anteriores. No recipiente da batedeira planetária (Kitchen Aid, modelo artisan) foi emulsionado o açúcar com a manteiga para formar um creme claro e aerado, utilizando o batedor globo em velocidade média por cerca de 5 minutos. Logo após, o ovo foi acrescentado e incorporado com o auxílio do utensílio raquete da batedeira em velocidade baixa. Depois foi acrescentado a farinha de trigo sarraceno misturada com o sal e o bicarbonato de sódio. Por último, foi misturado as nozes moídas e as gotas de chocolate (Callebaut $70 \%$ ) até a incorporação desses ingredientes à massa. Esta foi levada à geladeira por 20 minutos para e depois porcionando com uma colher com $35 \mathrm{~g}$ de massa sobre um tapete de silicone.

Todas as formulações foram assadas em forno turbo (marca Líder, modelo ventile E-6) a $160^{\circ} \mathrm{C}$ por 15 minutos. Depois de assadas foram esfriados sobre uma grade e 
embalados em potes hermeticamente fechados.

\section{Análise sensorial}

A análise sensorial foi realizada de acordo com a metodologia descrita por Meilgaard et al. (2007). O teste de aceitabilidade foi aplicado a um grupo de julgadores não treinados $(n=50)$ utilizando a escala hedônica estruturada de nove pontos (1 - desgostei extremamente; 9 - gostei extremamente).

O teste de intenção de compra das amostras foi realizado, utilizando a escala de 5 pontos $(5=$ certamente compraria, $3=$ indiferente, 1 = certamente não compraria) (DELLA TORRE et al., 2003).

\section{Análise estatística}

Os resultados foram analisados utilizando o programa Statistica ${ }^{\circledR}$ versão 8.0 (Statsoft Inc., Tulsa, OK, USA). As diferenças entre as médias foram calculadas através da análise de variância oneway (ANOVA) com o teste de Tukey. Foram consideradas significativas as diferenças ao nível de $5 \%$ (p $<0,05)$.

\section{RESULTADOS E DISCUSSÃO}

Durante a pesquisa foi observado o desconhecimento do público geral quanto ao uso do trigo sarraceno na culinária, bem como suas propriedades nutracêuticas e importância como um patrimonio cultural de Santa Catarina.

No teste sensorial, $67 \%$ dos julgadores foram mulheres. Do total de julgadores $4 \%$ relataram consumir biscoitos três ou mais vezes ao dia, $7 \%$ duas vezes e 11 $\%$ uma vez ao dia. Apenas $20 \%$ já conheciam o trigo sarraceno.

Na Figura 1 é possível observar as notas atribuídas pelos julgadores no teste de aceitabilidade. As notas atribuídas pelos julgadores no teste de aceitabilidade variaram entre "desgostei ligeiramente e gostei muitíssimo". 
Figura 1 - Aceitabilidade sensorial dos biscoitos com farinha de trigo sarraceno.

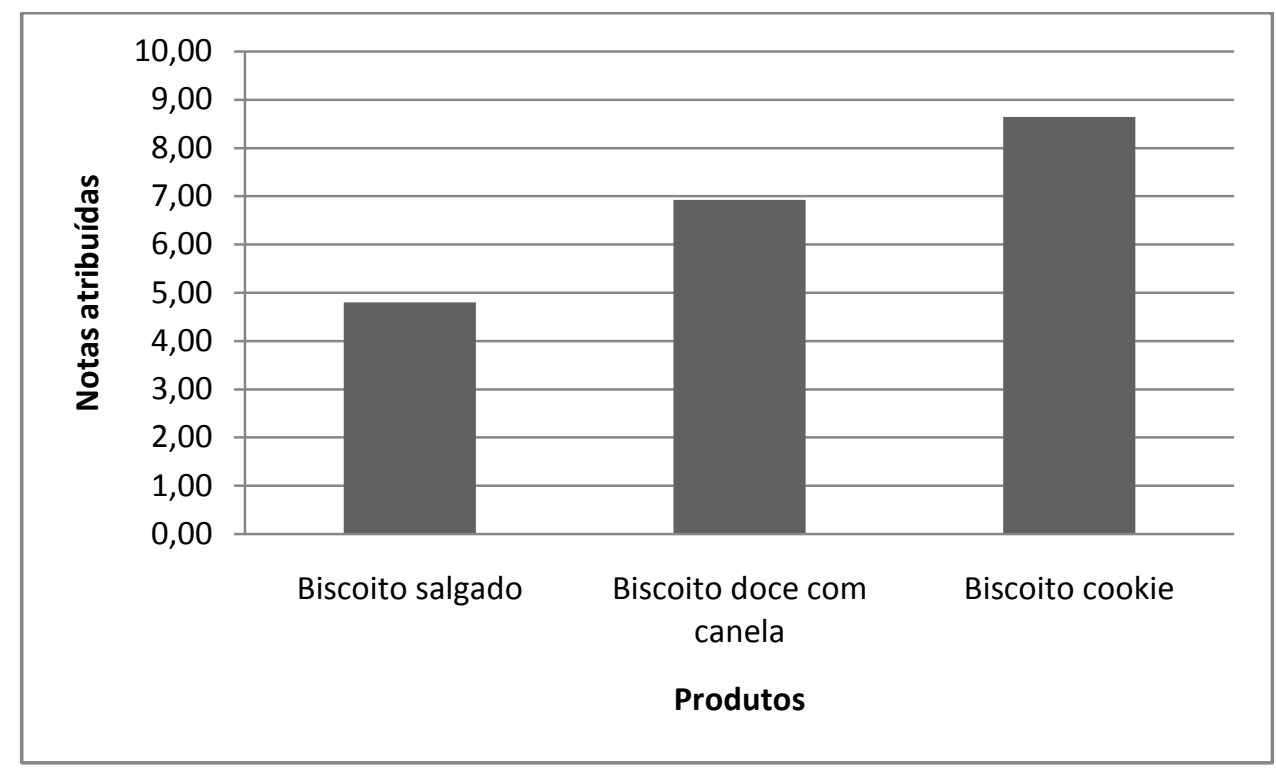

No teste sensorial foi observada diferença significativa entre os tratamentos $(\mathrm{P}$ $>$ 0,05). A amostra A, de biscoito salgado, obteve nota no teste de aceitabilidade de 4,80. Assim, considera-se que o produto não foi aceito, pois a média de aceitação foi menor que seis (DELLA TORRE, 2003). A amostra $\mathrm{B}$, de biscoito doce com canela, apresentou valor de 6,93, enquanto a amostra $\mathrm{C}$, de cookies, obteve a maior aceitabilidade sensorial com 8,64. Ambas foram aceitas. Os biscoitos estão ilustrados na Figura 2.

Figura 2 - Biscoitos produzidos com a farinha de trigo sarraceno.

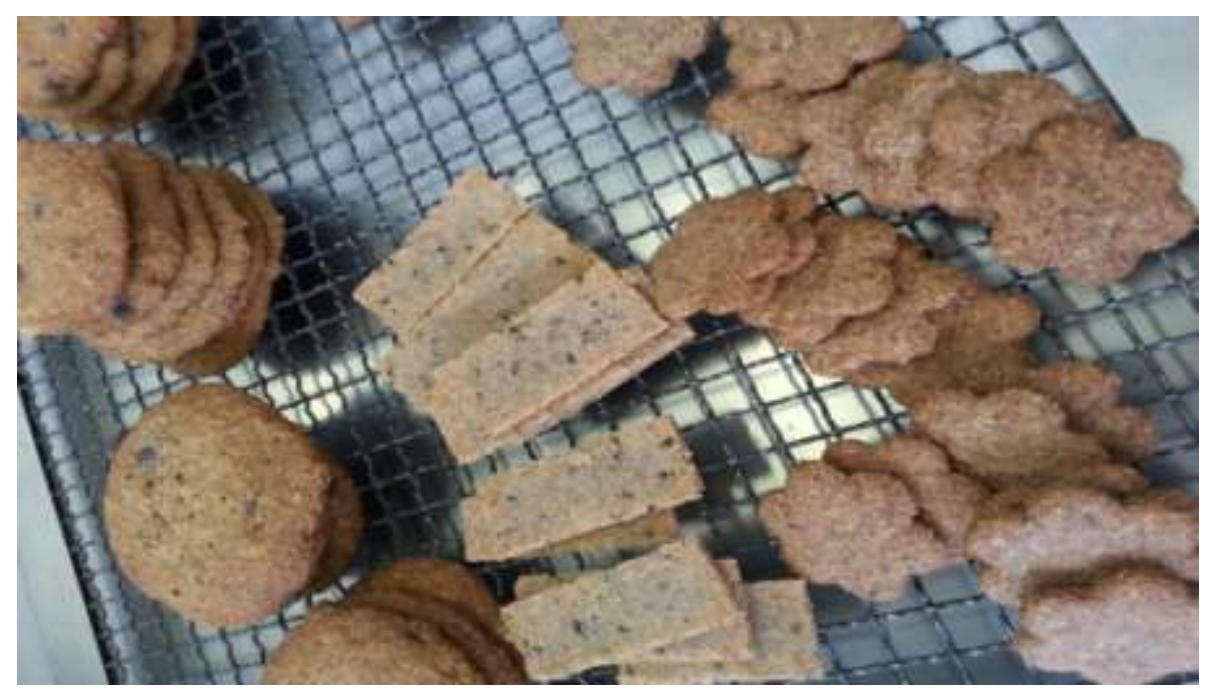

*Da esquerda para a direita: Biscoito tipo cookie, biscoito salgado e biscoito doce com canela.

Baljeet et al. (2010) analisaram as propriedades físico-químicas e funcionais da farinha de trigo sarraceno e elaboraram biscoitos incorporando 10, 20, 30 e $40 \%$ de 
sarraceno para avaliar a qualidade e aceitabilidade. Os biscoitos elaborados com adição de 20 e $30 \%$ de farinha de sarraceno obtiveram pontuação geral de aceitabilidade de 6,71 e 6,20, respectivamente, sugerindo aceitabilidade dos consumidores. A formulação dos biscoitos tiveram a mesma quantidade de açúcar e gordura na sua formulação, no entanto, a quantidade da concentração de farinha de sarraceno divergiu bastante. $\mathrm{Na}$ presente pesquisa todos os biscoitos foram elaborados com $100 \%$ de farinha de sarraceno sendo que o doce com canela (formulação B) teve 6,93 de aceitação, valor maior do que no estudo citado com 30 $\%$ de farinha de sarraceno.

Alguns estudos detectaram uma redução do valor atribuído ao sabor em concentrações maiores de farinha de sarraceno nas formulações. Este fato pode estar relacionado presença de flavonóides como a rutina, que confere sabor amargo na farinha (BALJEET et al., 2010; CHOPRA et al., 2014). Desta forma a rejeição do biscoito salgado elaborado com $100 \%$ de farinha de sarraceno pode estar relacionada ao sabor residual. Acredita-se que o biscoito salgado (formulação A) pode melhorar a aceitabilidade se for associada à formulação outra farinha e agregar outros atrativos como queijo ou especiarias.

Os resultados do presente trabalho mostram que os biscoitos do tipo cookie elaborados com substituição total da farinha de trigo pela da farinha de sarraceno possui grande aceitação por parte dos consumidores, que ainda não estão familiarizados com esse tipo de produto, mostrando o seu potencial comercial. O estudo de Chopra et al.(2014) substituiram a farinha de trigo por sarraceno até $75 \%$ na preparação de cookies. O resultado mostrou que a farinha de trigo sarraceno em biscoitos teve efeito considerável sobre as propriedades físicoquímicas e sensoriais de cookies. Concluíram que a farinha de trigo sarraceno pode ser incorporada até um nível de $75 \%$, para se obter cookie com atributos sensoriais aceitáveis.

Torbica et al.(2012) concluíram em seus estudos que as farinhas de arroz e trigo sarraceno podem substituir a farinha de trigo em cookies sem glúten. As misturas apresentaram composição química semelhante à farinha de trigo mas tamanho de partícula mais grossa. Os cookies com $20 \%$ de farinha de trigo sarraceno foram os que apresentaram maior aceitabilidade no teste sensorial.

Os resultados acima mostraram que a farinha de trigo sarraceno pode ser utilizada no desenvolvimento de receitas de biscoitos doces. É interessante o seu uso devido suas propriedades nutricionais e as suas características de formação de massa.

As amostras aceitas no teste sensorial foram submetidas ao teste de intenção de compra (Figuras 3 e 4). Com relação ao biscoito doce de canela, $11 \%$ dos julgadores 
relataram que certamente comprariam o produto e $35 \%$ que provavelmente comprariam. Já para o biscoito cookie, 83\% relataram que certamente comprariam o produto.

Figura 3 - Intenção de compra de biscoito doce com canela.

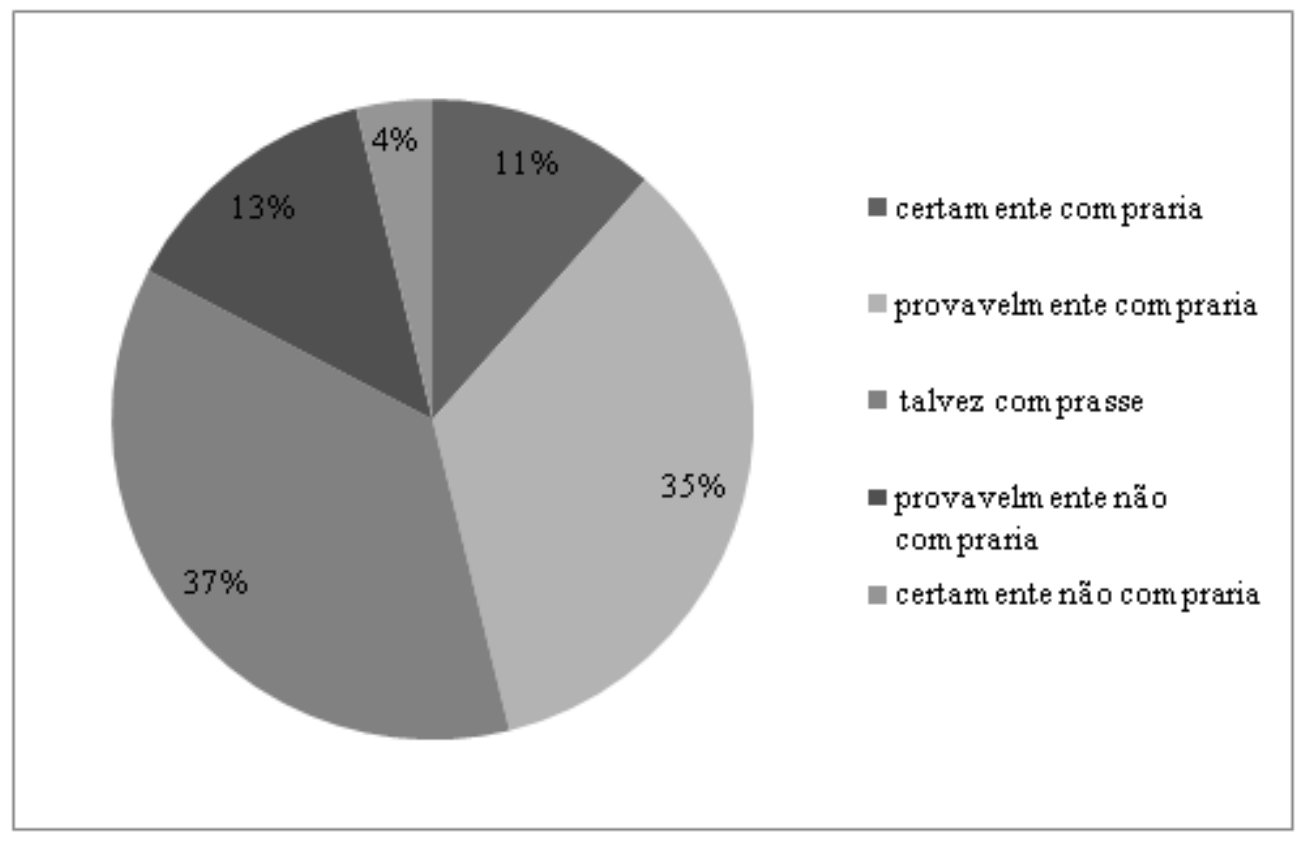

Figura 4 - Intenção de compra de biscoito cookie.

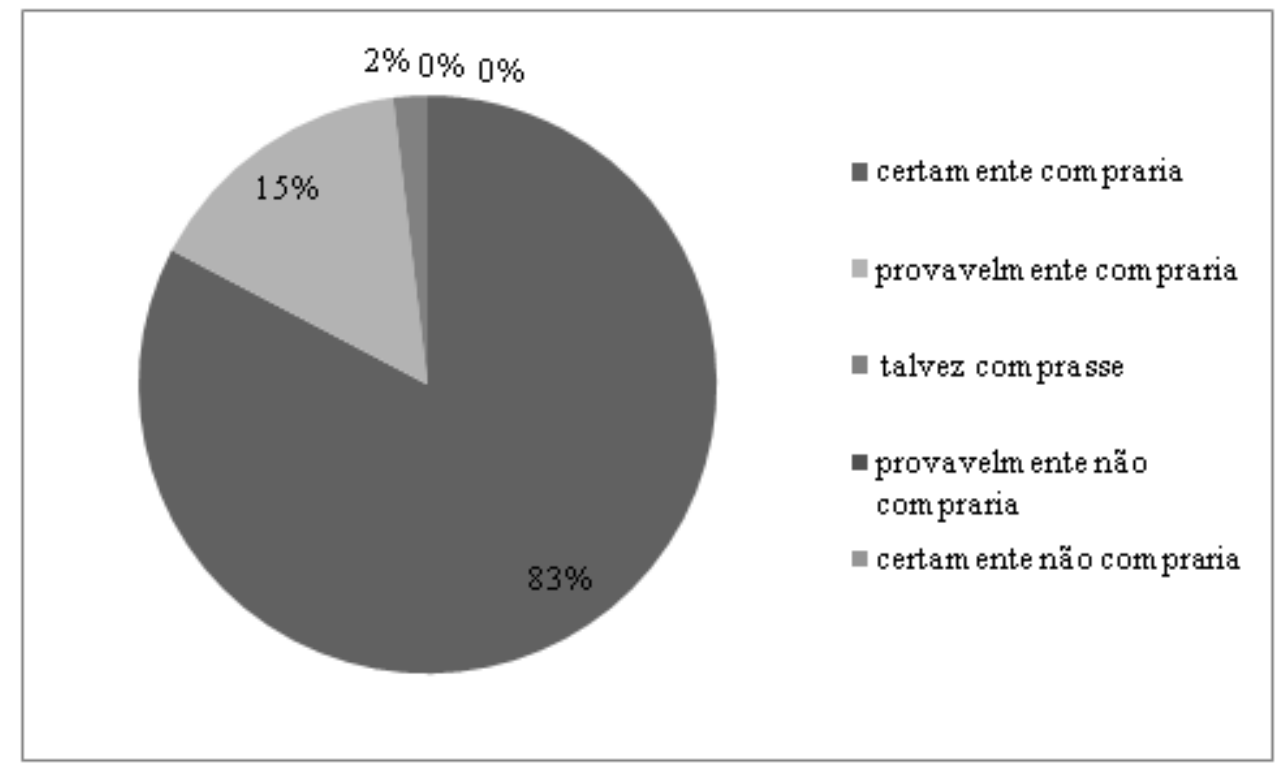

\section{CONCLUSÃO}

O uso do trigo sarraceno na nutritivos e com aceitação sensorial. Por ser preparação de produtos da gastronomia é produzido no Estado de Santa Catarina, 
também incentiva o desenvolvimento da agricultura familiar.

A elaboração de biscoitos doces com a farinha de trigo sarraceno tem potencial comercial, já que apresentaram uma boa aceitabilidade sensorial, especialmente $\mathrm{o}$ biscoito tipo cookie. Este resultado mostra a possibilidade do uso desta matéria prima na elaboração de produtos convencionais contribuindo para a difusão do trigo sarraceno.

\section{REFERÊNCIAS}

ALTIERI, M. A. Agroecologia, agricultura camponesa e soberania alimentar. Revista Nera, n. 16, p. 22-32. 2012.

ALVAREZ-JUBETE, L. et al. Polyphenol composition and in vitro antioxidant activity of amaranth, quinoa buckwheat and wheat as affected by sprouting and baking. Food Chemistry, v. 119, n. 2, p. 770-778. 2010.

BALJEET, S. Y. et al. Studies on functional properties and incorporation of buckwheat flour for biscuit making. International Food Research Journal, v. 17, p. 1067-1076. 2010.

BARBOSA, L. Tendências da alimentação contemporânea. In: PINTO, Michele de Lavra; PACHECO, J. K. (Orgs.). Juventude, consumo e educação. 2. ed. Porto Alegre: ESPM, 2009.

BAVEC, F.; BAVEC, M. Underutilized crops and intercrops in crop rotation as factors for increasing biodiversity on fields. 2014.

CAPRILES, V. D. et al. Efeito da adição de amaranto na composição e na aceitabilidade do biscoito tipo cookie e do pão de forma.
Alimentos e Nutrição, v. 17, n. 3, p. 269274. 2014.

CHOPRA, N. et al. Formulation of buckwheat cookies and their nutritional, physical, sensory and micro biological analysis.

International Journal of Advanced Biotechnology and Research. v. 15, n 3, p. 381-387. 2014.

CHRISTA, K.; SORAL-ŚMIETANA, M. Buckwheat grains and buckwheat productsnutritional and prophylactic value of their components - a review. Czech Journal Food Science, v. 26, n. 3, p. 153-162. 2008.

COMINO, I. et al. The gluten-free Diet: testing alternative cereals tolerated by celiac patients. Nutrients, v. 5, n. 10, p. 4250-4268. 2013.

CRUZ, F. T.; MENASCHE, R. Do consumo à produção: produtos locais, olhares cruzados. In: IDeAS. Programa de Pós-Graduação de Ciências Sociais em Desenvolvimento, Agricultura e Sociedade. Universidade Federal Rural do Rio de Janeiro, 2011. p. 124.

DELLA TORRE, J. C. M. et al. Perfil sensorial e aceitação de suco de laranja pasteurizado minimamente processado.

Ciência e Tecnologia de Alimentos, v. 23, n. 2, p. 105-111. 2003.

FAO. Statistician trade statistics, worldwide about buckwheat. Rome, 2000.

FREITAS, C. A. Sabor de tradição. Em parceria com agricultores de Itaiópolis, a EPAGRI recupera o cultivo do trigo mourisco, um alimento típico das culinárias polonesa e ucraniana. Revista Agropecuária Catarinense, Florianópolis, v. 26, n. 1. 2013.

GOODMAN, D. The quality 'turn' and alternative food practices: reflections and agenda. Journal of Rural Studies, n. 19, p. 1-7. 2003. 
HADNAĐEV, T. R. D. et al. Influence of buckwheat flour and carboxymethyl cellulose on rheological behaviour and baking performance of gluten-free cookie dough.

Food and Bioprocess Technology, v. 6, n. 7, p. 1770-1781. 2013.

JOHNS, T. et al. Biofortification, biodiversity and diet: A search for complementary applications against poverty and malnutrition. Food Policy, v. 32, n. 1, p. 1-24. 2007.

KLEIN, V. A. et al. Trigo mourisco: uma planta de triplo propósito e uma opção para rotação de culturas em áreas sob plantio direto. Revista Plantio Direto, v. 117, maio/jun. 2010. Disponível em: $<$ http://www.plantiodireto.inf.br/?body=cont_ int\&id=991 $>$. Acesso em: 10 set. 2015.

MEILGAARD, M. et al. Sensory Evaluation Techniques. 4. ed. Boca Raton, FL: CRC Press, 2007. 448p.

NASCIMENTO, A. B. Desenvolvimento de produto alimentício sem glúten elaborado a partir da percepção de consumidores celíacos. 2014. Tese (doutorado) Universidade Federal de Santa Catarina, Centro de Ciências Agrárias, Programa de Pós-Graduação em Ciência dos Alimentos, Florianópolis, 2014.

RODRIGUES, C. M.; OLIVEIRA, V. R. de. Utilização de farinha de trigo sarraceno em associação com farinha de arroz e soja na elaboração de minipizzas buckwheat flour associated to rice and soy flour to make mini pizzas. Alimentos e Nutrição, v. 21, n. 1, p. 21-24. 2010.

SCHOENLECHNER, R. et al. Pseudocereals. In: ARENDT, E. K.; BELLO, F. D. (Eds.). Gluten-free cereal products and beverages. London, San Diego: Elsevier, 2008. p. 149176.

SILVA, D. B. et al. Avaliação de genótipos de mourisco na região do Cerrado. Boletim de Pesquisa e Desenvolvimento. Embrapa Recursos Genéticos e Biotecnologia, 2002. TORBICA, A. et al. Rice and buckwheat flour characterisation and its relation to cookie quality. Food Research

International, v. 48, n. 1, p. 277-283. 2012.

VICENTE FILHO, R. G. A Triticultura e os Bens Culturais em Itaiópolis/SC: Algumas Reflexões. In: XXVII SIMPÓSIO NACIONAL DE HISTÓRIA: CONHECIMENTO HISTÓRICO E DIÁLOGO SOCIAL, 2013. Anais... Natal RN, 2013. 